\title{
Çin ile ABD Arasında Ticari Gerginlik: Rekabet Gücü Açısından Bir Bakış
}

Ziya Çağlar YURTTANÇıKMAZ Yasen REZIWANGULI ${ }^{2}$ Ömer Selçuk EMSEN ${ }^{3}$

\begin{tabular}{ccc}
\hline $\begin{array}{c}\text { Geliş Tarihi/ Received } \\
\text { 19/02/2020 }\end{array}$ & Kabul Tarihi/ Accepted & Yayın Tarihi/ Published \\
02/04/2020 & $15 / 04 / 2020$ \\
\hline Citation/Atıf: Yurttançımaz, Z., C., Reziwanguli, Y. ve Emsen, Ö., S., (2020), Çin ile Abd \\
Arasında Ticari Gerginlik: Rekabet Gücü Açısından Bir Bakış, Atatürk Üniversitesi İktisadi ve \\
Idari Bilimler Dergisi, 34(2): 649-667, DOI: 10.16951/atauniiibd.691267 \\
\hline
\end{tabular}

Özet: Çin ile ABD arasındaki dış ticaret ilişkileri değerlendirildiğinde, Çin'in genelde dünyaya ve özelde de ABD'ye karşı dış ticaret bilançosu açısından sürekli fazla verdiği dikkat çekmektedir. Dış ticareti de kuşatan cari işlemler bilançosu çerçevesinde bir değerlendirmesi yapıldığında, cari fazlanın dış ticaretteki kadar olmadığı görülmektedir. Dolayısıyla sürekli açık veren gelişmiş ekonomilerin tarife dışı araçlarla ve özellikle gönüllü ihracat kısıtlamaları olgusuyla tepki verdiği politika argümanının varlığı bilinmektedir. ABD'nin dış açığını kapatma amacı ve Çin'in giderek yükselen bir ekonomik güç olmasını engelleme düşüncesi yeni merkantilist uygulamalara yol açmaktadır. Çalışmada ana mal grupları itibarıyla Çin ile ABD arasındaki rekabet güçleri inceleme konusu yapılmıştır. Rekabet gücü açısından Çin'in yükte ağır, pahada hafif mallar grubunda rekabet gücünün olmadığ 1 dikkat çekmiştir. Bu durum oldukça geniş iç talepten kaynaklanabileceği düşünülmüştür. Ancak, bu grupta da ileriye dönük olarak rekabet gücü elde etme olasılığına dair sinyaller yakalanmıştır. Diğer taraftan genel anlamda emek-yoğun sektörlerde rekabet gücünün varlığı dikkat çekmekte ve bunun da makineler ve taşıt araçları ile çeşitli mamul eşyada olduğu gözlenmiştir. Bu iki mal grubundaki üstünlügün daha çok ucuz emek avantajı ile sürdürüldüğü söylenebilir.

Anahtar Kelimeler: ABD ve Çin ekonomisi, Balassa endeksi, Rekabet gücü.

Commercial Tension between China and USA: A View of Competitiveness

Abstract: When foreign trade relations between China and the USA are evaluated, it is noteworthy that China always gives a surplus in terms of foreign trade balance against the world and in particular to the USA. When an evaluation is made within the framework of the current account balance that encompasses foreign trade, it is seen that the current surplus is not as much as in foreign trade. Therefore, the existence of a policy argument is known that the developed economies that constantly open deficit react with non-tariff instruments and especially voluntary export restrictions. The aim of closing the foreign deficit of the USA and the idea of preventing China from becoming a rising economic power leads to new mercantilist practices. In the study, the

${ }^{1}$ Dr. Öğr. Üyesi, Atatürk Üniversitesi, İktisadi ve İdari Bilimler Fakültesi, İktisat Bölümü, https://orcid.org/0000-0001-7474-1096

${ }^{2}$ Yüksek Lisans Öğrencisi, Atatürk Üniversitesi, Sosyal Bilimler Enstitüsü, İktisat ABD, https://orcid.org/0000-0002-2459-9893

${ }^{3}$ Prof. Dr., Atatürk Üniversitesi, İktisadi ve İdari Bilimler Fakültesi, İktisat Bölümü, https://orcid.org/0000-0002-1809-0513 
competitiveness between China and the USA in terms of main goods groups has been examined. In terms of competitiveness, it is noteworthy that China has no competitive power in the heavy, expensive light goods group. This situation is thought to be caused by quite wide domestic demand. However, in this group, signals about the possibility of obtaining competitive power prospectively were caught. On the other hand, the presence of competitiveness in the labor-intensive sectors in general attracts attention, and this has been observed to be in machines and vehicles and various manufactured goods. It can be said that the superiority in these two commodity groups is maintained with the advantage of cheap labor.

Keywords: USA and Chinese economy, Balassa index, Competitiveness.

\section{EXTENDED SUMMARY}

The Chinese economy, which is the motivation of the study, is currently described as "the factory of the world". The economic development of China, which started in labor-intensive sectors, has also developed rapidly in the field of technology, and today, high-tech goods exports have reached a significant share in total exports.

Accompanied by this development, the "voluntary export restrictions" argument, which the US has applied from time to time, especially in the past, has started to be operated in China. During the "trade war" initiated in 2018, China has become a factor that threatens the economic hegemony by compressing the USA in terms of competitiveness. Therefore, competitiveness of China against the USA in terms of sub-sectors is worth examining. The data used in the study, which was the subject of determining the competitiveness of China and the USA in the top 10 commodity groups and examining the past industrial history of the two countries, covers the period between 1995 and 2016. The data used in the study were obtained from the data distribution services on the websites of the United Nations Conference on Trade and Development (UNCTAD). At this point, it is important to have competitive power in a certain product or sector compared to other countries in order to gain added value in foreign trade and gain added value in the globalizing economy world.

It is possible to summarize the findings obtained as a result of competitiveness calculations between the USA and China as follows:

- According to the BATTERY index of the main 10 commodity groups calculated against the USA, the Balassa index in the two commodity groups is seen to be greater than 1 , which shows that it has competitive power.

- In the other 8 commodity groups, the figures are less than 1 and therefore indicate that they do not have competitive power. In four of the sectors with weak competitiveness in China, there are improvements in competitiveness against the USA. It can be said that the obvious disadvantaged structure observed at the beginning tends to become neutral in time.

When an assessment is made in terms of the general situation of the US industry of China, it is observed that China is still more labor intensive against the USA. It is noteworthy that in recent times, competitiveness is a trend in favor of China in capital and technology-intensive goods. The existence of a labor warehouse in China, which can be called important in the countryside, points to 
the potential to maintain labor-intensive growth. However, in order for China to have competitive power especially against developed countries, it has to be developed in the field of capital density and high technology. For this reason, it is necessary to attach importance to $\mathrm{R} \& \mathrm{D}$ and ensure continuity in productivity increase.

Çin'in 1970'lerin başlayan ve günümüze kadar sürekli yenilenen ekonomik reform politikası sonucu, 2017 yılında ülkenin dolar cinsinden ihracatı 2 trilyon 260 milyar dolara ve ithalatı da 1 trilyon 840 milyar dolara ulaşmış durumdadır. Mevcut veriler sürekli dış fazla veren Çin ekonomisinin en önemli dinamiği olarak ülkenin rekabet gücünün sürekli ilerlediği yönünde bir çıkarımda bulunma imkânı sağlamaktadır. Bu olguyu besleyecek şekilde özellikle ABD ile olan ilişkilerde yaygın ifadesiyle "ticaret savaşı"nın başlamış olması da buna delil teşkil ettiği söylenebilir. Dolayısıyla Çin ekonomisinin dış fazla ve yüksek büyümeye dayalı performansının başlangıçta daha çok emek-yoğun büyüme formatında olduğu ve böylece rekabet gücünün de sahip olduğu emek gücüne dayalı bir karşılaştırmalı üstünlük yapısına bağlı olduğu yapının değişimine işaret ettiği söylenebilir. Çin'in bu dönüşümünde Deng Xioping' in ekonomi konusunda yetkilendirilmesi önemli rol oynamıştır. 1970'lerin sonunda ortaya çıkan reformist süreçlerin tümü de "açık kapı politikası (open-door policy)" olarak adlandırılmıştır. Bu tarihi izleyen 30 yıl içerisinde olağanüstü bir şekilde dünyanın en kalabalık ülkesinin, yoksul ve durağan bir sosyalist ekonomiden dünyanın en dinamik ekonomisine dönüşümü söz konusu olmuştur (Coase ve Wang, 2015; Acemoğlu ve Robinson, 2014). Bu dönüşümle birlikte Çin'in zamana bağlı olarak sermaye ve teknolojik yoğun alanlara kayıp kaymadığı, büyümenin ve dış ticaretteki artışların sürdürülebilir olup olmadığ incelemeye değer bir konu olduğu söylenebilir. Çin'in bu türden bir gelişme gösterip göstermediği, dünya ekonomisinin önemli bir gücü konumunda olan ABD ekonomisi özelinde karşılaştırmalı olarak ele alınabileceği düşünülebilir. Dolayısıyla dış fazla veren Çin ekonomisine göre sürekli dış ticaret açığı veren ABD ekonomisinin en önemli sorunu ise giderek artan dış borç sorunsalıdır.

$\mathrm{Bu}$ çalışmada, yükselen ekonomiler bağlamında Çin'in, ticari mallar kapsamında dünya pazarındaki üstünlüğüne karşılık ABD'nin konumu ortaya konulacaktır. Çalışmanın birinci bölümünde $\mathrm{ABD}$ ve Çin ekonomilerinde zamana bağlı olarak gelişim verilecektir. İkinci bölümde rekabet gücü kavramı ve tanımlamalarına temas edilerek Balassa tarafından geliştirilen Açıklanmış Karşılaştırmalı Üstünlük (AKÜ) Endeksi de daha ayrıntılı bir şekilde ele alınmış ve gelişimi açıklanmaya çalışılmıştır. Üçüncü bölümde ise literatür araştırması yapılarak, Balassa endeksi ile yapılan rekabet gücü ölçümlerine yer verilmiş ve devamında da 1995-2018 arası dönem için Çin-ABD rekabet güçleri hesaplanmıştır. Çin ekonomisinin emek-yoğunluklu yapısının evrilerek sermaye ve teknoloji yoğunluklu yapıya dönüşüp dönüşmediği hususu tespit edilerek, 
ticaret savaşı olgusu rekabet gücü açısından tutarlı bir gerekçeye kavuşulacaktır. Sonuç kısmında ise özellikle Çin ile ABD arasında ortaya çıkan ve ekonomik temelleri olan gerginlik boyutunun rekabet gücünde Çin'in üstünlük derecesinin etkili olup olmadığına yer verilecektir.

\section{ABD ve Çin Ekonomisinin Son Asırdaki Gelişmeleri}

Çin'in halihazırda ABD'den sonra dünyanın en büyük ikinci ekonomisi konumuna gelmesi, kuvvetle muhtemel $\mathrm{ABD}$ açısından ekonomik ve buna paralel olarak siyasal gücün kaybı anlamı taşıyacağı düşündürücüdür. ABD'nin iki büyük dünya savaşı sonrasında ortaya çıkan hegemonik gücü 1991 yılına kadar Doğu Blokuna karşı Batı Blokunun liderliğiyle yürütülmüştü. Ancak, 1991'de Sovyetlerin dağılması ile birlikte iki kutuplu bir dünyadan ABD merkezli bir dünya anlayışı kuvvetle muhtemel görece daha az risk içeren bir yapı anlamı taşımıştır. Hatta Sovyetlerin çöküşüne bağlı olarak Fukuyama (1999) "Tarihin Sonu ve Son İnsan" adlı eseri ile en temel ekonomik ve siyasal rejim türü olarak liberalizmi önerecek şekilde görüşleri de yaygınlaşmaya başlamıştır. Buna karşıllk 1950'lerde Mao ile komünist rejime yönelen Çin, sosyalist uygulamalarla kalkınma çabalarını sonuçlandıramamış ve Mao'nun ölümüyle birlikte dış ekonomik ilişkilerde kontrollü liberal uygulamalara yönelerek geçmişte Sovyetler ile Japonya'nın başardığını gerçekleştirerek mucizevi denilebilecek büyüme atılımı sağlamıştır. Gelinen noktada Çin'e biçilen emek-yoğun alanlarda dünya fabrikası olma rolünün dışına çıkma endişeleri, bir kez daha ABD özelinde hegemonyacı güç olma özelliğinin tartış1lır olacağı savı gündemdedir.

\subsection{ABD Ekonomisinde Gelişmeler}

I. Dünya Savaşı sonrasında, savaş öncesi egemen güçlerden Almanya kesin bir yenilgiye uğratılmış, Rusya Bolşeviklerin öncülüğünde tecrit içerisine sokulmuş; 1919'da en güçlü olanı ABD ise diplomasi sahnesinin merkezinden çekilmeyi tercih etmiştir. Savaşın yol açtığ genç işgücü kaybına bir de doğum oranlarındaki dramatik düşüşün yol açtığı "doğum açıkları" eklenmiş, ülkelerin dış borç stokları devasa nispette artmış, imalat sanayi savaş öncesi seviyeye ancak 1920'lerin ortalarında gelebilmiştir. ABD'nin savaş yorgunu olmayan dinamik yapısına karşı1ık, dünya ekonomisinde dış borç ve savaş tazminatlarını ödemeye dayalı rekabetçi devalüasyon ve yeni merkantilist uygulamalar ile ABD'ye yönelik tarım ürünleri ihracatında kısıtlamaların yansıması olarak 1929 Büyük Buhranı patlak vermiştir. Krizden çıkma çabaları da 1932 Ottowa Konferansında sterlin bloku, Fransa'nın öncülüğünde altın bloku, Japonya' ya dayalı yen bloku Roosevelt'in altından vazgeçmesiyle dolar bloku ve "tek ülke içinde sosyalizm" modelini oluşturan SSCB varlığ 1 belirginleşmeye başlamıştır. Güç blokları oluşurken, buhrandan çıkış arayışları içinde sosyalist blokun başarısına karşı geliştirilen ve popüler tanımlamasıyla Keynesyen ya da New Deal (1928-1932 bunalımı sonrası ABD ekonomisinin yeniden inşası için Roosevelt'in hayata geçirdiği ekonomi ile ilgili bir dizi yasa) politikaları, bilinen iktisat anlayışını ters yüz etmiştir (Kennedy, 1990: 323-350). 
ABD ekonomik anlamda içe yoğunlaşarak bir dev olma yolunda giderken, dışta özellikle silah pozisyonu itibarıyla bir orta sıklet olarak kalmayı tercih etmiştir. Ancak, 1937-1938'de dünyada gerginleşme sinyalleri ile birlikte silahlanmaya daha fazla kaynak ayırma noktasına geçebilmiştir. Özellikle kriz öncesi ulaşılan yüksek kapasitenin varlı̆g 1 ABD'yi "uyuyan bir dev" olarak adlandırılmasına yol açmıştır. II. Dünya Savaşı'nda Hitler'in önce Rusya ve devamında ABD'ye savaş ilanı aslında iki kutuplu bir dünyanın da habercisi olmuş; ABD ve SSCB birinci derecede askeri güç haline gelmiş; De Tocqueville'in ifadesiyle "yerkürenin yarısının kaderini değiştirme gücüne sahip ülkeler olarak yalnızca ABD ve SSCB" olmuştur. Burada en önemli güç unsuruna ulaşmaları hususunda, her iki ülke için de coğrafi konum ve genişlik ile çok büyük harp malzemeleri potansiyelinin bir arada bulunmasından kaynaklandığı söylenebilir. ABD özelinde dikkati çeken en önemli unsur, uyuyan devin uyanmasıyla birlikte 1941-1943 arasında silah verimliliğinde gözüken 8 katlık artıştır. Bir kez daha Avrupa büyük bir savaştan ağır yaralarla çıkarken, yorulan güçlere karşı sonradan savaşa giren $\mathrm{ABD}$, hem siyasal anlamda hem de ekonomik anlamda diğer güçlerin önüne geçen bir güç konumuna gelmiştir (Keetnnedy, 1990: 386-428).

ABD, savaş sonrası çöken güçler içinde başta gelen İngiltere'nin yerini almış ve buna bağlı olarak oluşan iki kutuplu dünyada Bretton Woods konferansları sonucu liberal düşünce ve buna bağlı olarak dışa açıklığın öncüsü konumuna gelerek askeri anlamda da NATO ile güvence arayışı içinde olmuştur. Böylece Batı Bloğunda SSCB yanlısı olabilecek komünist faaliyetler sınırlandırılabilmiştir (Kazgan, 2005: 13). Sovyetler ise yayılmacı kapitalizme karşı kapalılığın öncüsü olmuş ve Varşova Paktı ile askeri güvence oluştururken, 1953 'de Doğu Almanya'da ve 1956'da Macaristan'da baş gösteren isyanlara karş1 1961'de Khrushchev, yetenekli kişilerin Batı'ya akışını durdurmak için 1961'de Berlin Duvarının inşasını tetiklemiş̧ir (Kennedy, 1990: 445). İki kutuplu dünyanın sembolü haline gelen Berlin Duvarı aynı zamanda Doğu ile Batı arasındaki geçişkensizliğin ve gerilimin de sembolü halini alırken, aynı zamanda bu sınırların ötesine, yani yayılmacılık mücadelesinin de donesi olarak görülmüştür. Karşılıklı yayılmacılığa karşı düşman kavramı ile hem içte toplumu konsolide etme hem de dışa karşı taraftar arayışı için silah gösterileri ve propagandanın yaygın bir şekilde kullanıldığı dikkat çekmiştir. Özellikle Sovyetlerin dağılmasından sonra Hungtington'ın "Medeniyetler Çatışması" adlı eserinde de görüleceği üzere yenidünyada mücadelenin esas kayağının ideolojik ve ekonomik olmayacağı, asıl mücadelenin kültürel olacağı yönündeki tezidir. Medeniyetlerin de birbirinden ayıran unsurlar ise tarih, dil, kültür, gelenek ve en önemlisinin de din olduğu ifade edilir (Huntignton, 2000: 22, 25). Berlin Duvarının Yıkılması öncesinde Batıda toplumu konsolide etme eğiliminin bir aracı olarak "kızıl düşman" algısının bilinçli bir şekilde yaratıldığı ve sürekli ön planda tutulduğu dikkat çekerken, halihazırda bunun ideolojik boyuttan kültür boyutuna evrildiği husus ise farklı bir konudur. Zira Batı kendisine mal ettiği 
medeniyet hususunun kökeninde Batının Doğudan bilgi devşirmesi ve bunu sentezleyerek bir adım ileriye taşıdığı gerçeğini ihmal edilmektedir (bkz. Ülken, 2016: XII; Maalouf, 2012: 239-242). SSCB-ABD gerginliği SSCB'nin çöküşüyle ABD’yi dünyanın hegamonik gücü pozisyonuna getirmiştir.

\section{2. Çin Ekonomisinde Gelişmeler}

Adeta tarihi kökenleri itibarıyla kadim bir uygarlık olan Çin'in özellikle Sanayi Devrimi sürecinin dışında kalmasına paralel olarak Avrupa'nın sanayileşen ülkelerinin hammadde kaynağı konumuna gelmiş ve bundan kurtuluş çabaları da Mao'nun önderliğinde Komünist Devrim ile hayat bulmaya çalışmıştır. Ancak, Komünist Devrimin Çin'in gelişme dinamiklerinin sağlayamadığı gözlenirken, 1970'lerin sonunda yine Komünist Parti bünyesinde ortaya çıkartılan yapısal dönüşüm çabalarının yansımaları arasında günümüzde "Çin Mucizesi" veya "Dünyanın Fabrikası" olma gibi payelere erişimi söz konusu olabilmiştir.

II. Dünya Savaşı öncesinde Çin'de yükselen milliyetçiliğe karşı Japonya panzehrini kullanma eğiliminde olan bir İngiltere, buna ilaveten Japonya'nın stratejik avantaja sahip olduğu bir bölgede imparatorluk savunmasının zafiyetine karşı geliştirilen politika uygulayıcısı olarak dikkat çekmiştir. Çin'in 1978'den önceki hamleleri, Sovyet sisteminin mantı̆̆ına dayalıydı. SSCB 1928 sonrasında kendi kaynaklarını kullanarak tüketim ve yatırım mallarına dayalı (ağır sanayi, kömür, çelik ve çimento) hamleleri II. Dünya Savaşı sonrasında da sürdürülmüş, ulaşıma ağırlık verilmiş ve savaş harcamalarındaki kısıntının yansıması 19451950 arasında ağır sanayide ve verimlilikte iki katı artış sağlayarak bir mucize gerçekleştirmiştir (Kennedy, 1990: 392, 425).

Çağdaş Çin'in en belirgin özelliği olan ekonomik reform sayesinde, yepyeni bir sosyalist yola çıkmış ve Doğuda büyük bir ülke olarak ayağa kalkmaktan zenginleşmeye kadar tarihsel bir sıçramaya ulaşmıştır. Reform başlatılmasının nedeni ise Çin'in acımasız bir şekilde maruz kaldığı "10 yıllık Kültür Devrimi"nin beklenen başarıyı sergileyememesidir. 1960'lardaki "Kültür Devrimi”nin sonuçlarına bakıldığında da, ülkenin kalkınma durumunda ciddi problemlerinin mevcut olduğu dikkatleri çekmiştir. Dünyadaki gelişmiş ülkeler üçüncü bilimsel ve teknolojik devrime girip ekonomilerini hızla geliştirirken, Çin'in bu gelişim trendi dışında kalamayacağı ve dolaysıyla çağı yakalaması için reform yapmaktan başka çaresinin olmadığı genel kabul görmeye başlamıştır ( $\mathrm{Li}$ $\mathrm{Li}, 2018$ ).

Uluslararası bir bakış açısıyla, 1970'lerde Batılı kapitalist ülkeler üçüncü bilimsel ve teknolojik devrim geçirmekteydiler. Bilimsel ve teknolojik devrimin etkisiyle, Batılı kapitalist ülkelerin bilimsel ve teknolojik gücü büyük ölçüde artmış ve ekonomik gelişmede büyük mesafeler kat etmişlerdi. Çin'in iç durumu ise; ekonomi durgun, siyasal sistem yıkılmış, kültürel yapı gelişememiş, sosyal yapı geri kalmış ve genel ulusal güç ve devlet gücü Batılı kapitalist ülkelerin gerisinde kalmıştı. Bu gibi zıtlıklar altında, Çin'in gelişimi muazzam uluslararası 
çevresel baskıyla karşı karşıya kaldığından, yaşanan bu olumsuzluklara karşı reformsuz bir çıkış yolu gözükmüyordu. Gelişmiş kapitalist ülkelerle karşılaştırıldığında, Çin'in ekonomik ve teknolojik seviyesi genellikle 20 yıl gerideydi (Gu Mu, 2009). Gelişmişlik farkını açıklamak üzere; Deng Xiaoping'in Japonya gezisinde, işçi başına yılda 94 araba üretimine karşıllık Çin'in en gelişmiş fabrikasında yılda işçi başına sadece 1 araba üretimi olguyu özetliyordu. Konuyu Deng Xiaoping'in şu ifadelerinde özet olarak görmek mümkündür: "Gelişmiş ülkelerle karşılaştırıldığında, verimlilik gelişimindeki boşluk 10 yıllık bir sorun olmayabilir. Bazı yönlerde 20 yıl ve 30 yıl, bazı yönlerde 50 yıl bile olabilir" (Deng Xiaoping, 1994). Sorunu teşhis ederken, Deng Xiaoping'in Çin'in güvenini yeniden kazanabileceğini ve kendi boşluklarını telafi etmek için geri kalmışlığını başkalarından alçakgönüllülükle öğrenebileceğine temas etmiştir. $\mathrm{O}$ zamanlar Çin için tek çıkış yolu; reformları hızlandırmak ve açılmak, gelişmiş ülkelerle kalkınma açığını telafi etmek, onların gelişim hızlarını yakından takip etmek ve çağın tarihsel gelişimi aşmaktı.

1978'de devletin çalışma odağı, ekonomik yapıya kanalize edildi ve reform çağrısı resmi olarak başlatıldı. Ekonominin daha fazla canlandırılması ve dış dünyaya açılması ile şehirdeki bütün ekonomik sistemin reformunun hızlandırılması ve girişimin canlılığının güçlendirilmesi önerilmektedir. Sanayileşmenin bu dönemdeki temel özellikleri şunlardır; önceki ve tek taraflı ağır sanayinin gelişimden, kademeli olarak tarımsal, hafif ve ağır sanayi şeklinde bir dönüşüm ayarlanmış, tüketim malları sanayinin gelişimi önemli bir konuma getirilmiştir. Enerji verimliliğinin iyileştirilmesi, enerji endüstrisi ve ulaştırma endüstrisinin güçlendirilmesi yönünde adımlar atılmıştır. Genel olarak, bu aşama sanayileşmenin erken aşaması olarak adlandırılmıştır (Han ve Yang, 2019).

1993-2002 arası dönemde finansal, işgücü, emlak, teknoloji ve bilgi piyasasına odaklanan piyasa sistemi kademeli bir şekilde kurulmuş ve geliştirilmiştir; sanayileşmenin hızlı ilerlemesi için yeterli sermaye, emek ve teknik destek sağlanmıştır. 2002 yılında "bilgi teknolojisiyle sanayileşmeyi yönlendirmek, sanayi ile bilgi teknolojisini desteklemek ve yüksek teknoloji ve ekonomik fayda sağlamak" için sürdürmeyi gerektiren "yeni sanayileşme" önerisinde bulunulmuştur. Böylece düşük kaynak tüketimi, daha az çevre kirliliği ve insan kaynaklarının tam kullanımı ile yeni bir sanayileşme yolu benimsenmiştir: " $\mathrm{Bu}$ stratejinin rehberliğinde 2003'ten 2012'ye kadar Çin'in GSYIH'si yıllık ortalama \%10'dan daha fazla bir oranda artmıştır. 2010 yılında Çin ekonomik büyüklük olarak Japonya'yı da geçerek dünyada ikinci sırayı almıştır (Han ve Yang, 2019).

2013 yılında, Çin'in yüksek sanayi sektörünün GSYİH'ye katma değeri $(\% 46,1)$ ilk kez ikincil sanayiyi $(\% 43,9)$ aşmış ve ulusal ekonomideki en büyük sektör sanayi sektörü olmuştur. Bu dönüm noktası değişikliği aslında Çin'in sanayileşmenin son aşamasına girdiğine işaret etmektedir. 2013'ten 2018'e kadar, Çin'in ekonomik büyüme oranı, $\% 8$ ila $\% 10$ arasındaki yüksek hızlı büyüme aralığından \%6 ila \%7 arasındaki orta yüksek hızlı büyüme aralığına 
düşmüştür. Yavaş büyüme oranı, daha iyi yap1 ve güç dönüşümü ile "yeni ekonomik normallik" özellikleri sergilediği söylenebilir (Han ve Yang, 2019).

Son 70 yıldaki sanayileşme süreci boyunca, üç sektörün yapısal evrimi açısından bakıldığında, Çin'in sanayileşmesi temel olarak Petty Colin Clark teoremine uygun bir seyir izlediği görülmektedir. Birincil sektörün katma değerinin oranı 1952 'de $\% 50,5$ 'ten 2018 'de $\% 7,2$ 'ye; ikincil sektörün katma değeri 1952 'de $\% 20,8$ 'den 2006 ' da $\% 47,6$ 'ya yükselmiş ve ardından da düşmeye başlamış, 2018 'd e\%40,7 olmuş; üçüncül sektörün katma değeri ise 1952'de \%28,7'den 2018'de \%52,2'ye ulaşmıştır. Sanayiin içyapısından bakıldığında, Çin'in sanayileşmesi ilk önce hafif sanayi ile başlamamış, ancak devlet ağır sanayinin gelişmesine öncelik vermiş ve ağır sanayileşmenin öncelikli gelişimi hafif sanayinin hızlı gelişimi - hafif ve ağır sanayilerin koordineli gelişimi - ağır sanayinin yeniden gelişimi deneyimlemiştir. 70 yıllık zorlu çalışmaların ardından Çin, tüm endüstriyel üretim yeteneklerine sahip bir ülke haline gelmiş ve bugün dünyada 500 büyük sanayi ürününün 220'den fazlasında birinci sırada yer almış ve "Çin malı" dünya çapında 230'dan fazla ülkeye girmiştir. Birleşmiş Milletler İstatistik Bölümü veri tabanının istatistiklerine göre, 2016 yılında, Çin'in imalat sanayinin katma değeri 307.985 milyar ABD dolarına ulaşarak dünya toplamının $\% 24.5$ 'ini ve dünyanın ikinci en büyük $\mathrm{ABD}$ imalat katma değerinden yaklaşık 1 trilyon dolar daha fazlasını sağlamıştır. Şu anda, Çin sanayileşmenin geç aşamasına girmiştir ve 2035 'ten sonra sanayileşmenin tam olarak gerçekleşmesi beklenmektedir ve bu da dünyadaki üretim güçlerinin orta seviyesine ulaşma anlamı taşıyacaktır (Huang, 2018). Bu nedenle, güçlü sanayi, özellikle ileri imalat endüstrisinin güçlendirilmesi, gelecekteki ekonomik kalkınmanın belirlenmesinde hala kilit önemde olduğuna işaret etmektedir.

\section{3. Çin ve ABD Arasında Temel Ekonomik Göstergelerde Gelişmeler}

$\mathrm{ABD}$ ve Çin arasındaki son dönemlerde ortaya çıkan çekişme, aslında liberalizmi ve dolaysıyla diş ticareti savunan $A B D$ açısından manidardır. Zira gelişmiş ülkeler dış ticaretin yararlarını savunurken, kendisinin yüksek katma değerli ürünlerde rekabet avantajına karşıllk, düşük katma değerli ürünleri geriden gelen diğer ülkelere bırakması, uluslararası işbölümü ve buna bağlı olarak refahı artıracağına dair en temel liberal ilkedir. Burada Dünya Bankasından elde edilen veriler kullanılarak Çin ile ABD ekonomisine ilişkin bir kısım temel göstergelerden hareketle gelişim ortaya koyulmaya çalışılmıştır. 


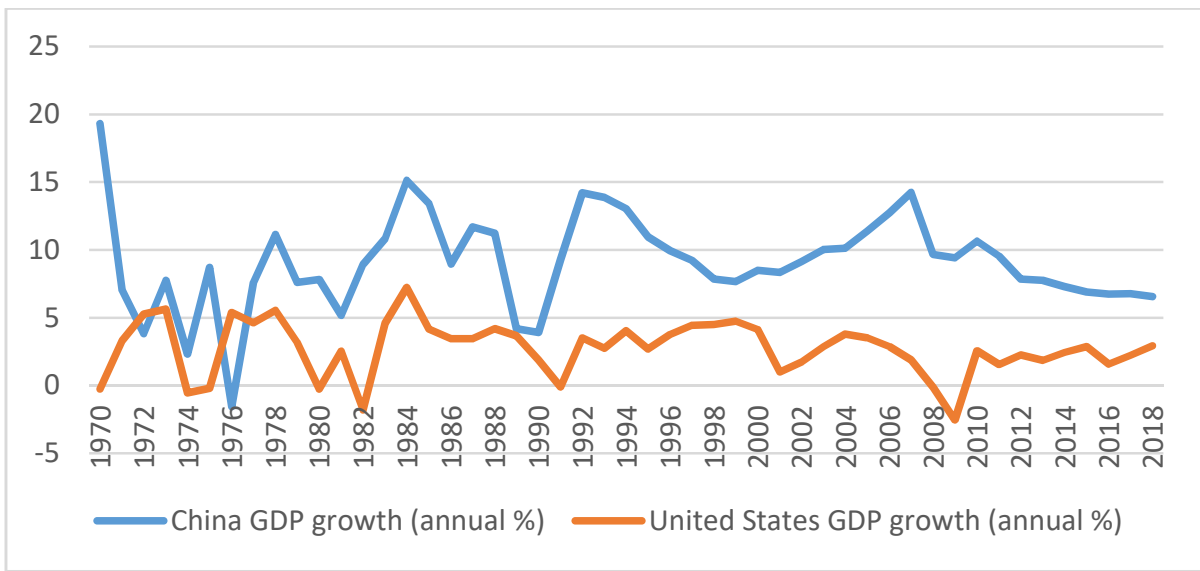

Şekil: 1 Çin ve ABD GSYIH Büyüme Hızları

Çin'in sergilediği yüksek büyümeye karşılık, başta ABD olmak üzere gelişmiş ülkelerin ona biçtiği rolün dışına çıkıp çıkmama olgusunu belirleyecek unsur ise ancak rekabet gücündeki gelişmelerle ortaya konulabilir.

\section{Rekabet Gücü Kavramı ve Ölçümü Literatürü}

Tam bir konsensüs sağlanamamış olsa da en genel tanımlamasıyla "rekabet gücü, göreli olarak herhangi bir ülkedeki bir sektörün diğer ülkelerin ayn1 sektörlerine göre daha yüksek gelir ve istihdam yaratma gücüne sahip olmasıdır". Uluslararası rekabet gücü tanımı üzerine birçok farklı görüş olmasına rağmen, ulusal rekabet gücü, endüstriyel rekabet gücü ve işletme rekabet gücü, yani makro ve mikro olmak üzere ayrı ayrı uluslararası rekabet gücü tanımının bir özeti ortaya koyulabilir. Ulusal rekabet gücü, endüstriyel rekabet gücü ve kurumsal rekabet gücü arasında tamamlayıcı bir ilişki vardır. İşletme rekabet gücü ve endüstriyel rekabet gücü, ulusal rekabet gücünün temelini oluşturmaktadır. İşletmenin rekabet gücü, endüstrinin rekabet gücünü belirler; endüstriyel rekabet gücü, ulusal rekabet gücünü ve ulusal rekabet gücü de endüstriyel rekabet gücü ve işletme rekabet gücü üzerine etki yapar. İşletme rekabet gücünün ve endüstriyel rekabet gücünün iyileştirilmesi, sonuçta ulusal rekabet gücünün arttırılmasına bağlıdır (Peng Yu, 2010).

Rekabet gücü ölçümü konusunda Durand ve Giorno (1997) ideal olarak, rekabet gücü ölçülmesinin üç prensibi yerine getirmesi gerektiğinden bahsetmişlerdir: Birincisi, rekabete katılan tüm sektörleri ve bölümleri içermeli; ikincisi, tüm açık rekabet piyasalarını kapsamalı; nihayet üçüncüsü de, tamamen uluslararası karşılaştırmayı sağlayan verilere dayanmalıdır. Aslında, mevcut göstergelerin hiçbiri yukarıdaki üç koşulu tam olarak yerine getirememektedir. Bu nedenle, halihazırda herhangi bir rekabet gücü ölçüsü, ideal ölçümün oldukça kaba sayılacak bir yaklaşımı konumundadır. Dolaysıyla rekabet gücünü ölçen yaklaşımlar da kendi içerisinde tutarlı olmakla birlikte, ölçüme bağlı olarak eksiklikleri de bünyesinde taşımaktadır. Bu noktada cari literatürdeki göstergeleri 
ana başlıklar şeklinde şu şekilde sıralamak mümkündür (Reziwanguli, 2019: 913): (i) Kârlılık ve Pazar Payı Göstergeleri, (ii) Maliyet Göstergesi, (iii) Kapsaml Rekabet Gücü Endeksi, (iv) Açıklanmış Karşılaştırmalı Üstünlük Endeksi (RCA), (iv) Verimlilik ve Büyüme Göstergeleri, (v) Reel Döviz Kuru Göstergeleri, (vi) Doğrudan Yabancı Yatırımlar Göstergesi.

Bir ülkenin bir başka ülke veya ülkelere göre mal ve hizmetlerde karşılaştırmalı üstünlüğünün hesaplanmasında, karşılaştırmalı üstünlükleri belirleyen fiyat ve fiyat dışı unsurların; kapsadığı ülke, ürün ve hizmet sayısı çok olduğundan, ticaret sonrası verileri kullanmak daha uygun görülmüştür. Buna yönelik ilk çalışma Liesner (1958) tarafından yapılmış ve Balassa'nın (1965) geliştirdiği Açıklanmış Karşılaştırmalı Üstünlükler (Revealed Comparative Advantage -RCA- AKÜ) endeksi en sık kullanılan endeks haline gelmiştir. Balassa endeksi ise ülkenin belli mal, hizmet veya endüstrisinin karşılaştırmalı üstünlügünün hesaplanmasında, bu mal, hizmet ya da endüstrinin toplam dünya ihracatındaki payının, ülkenin toplam ihracatındaki payına oranlanmasından ibarettir. Balassa'nın oluşturduğu formül şu şekildedir:

$$
\mathrm{AKÜ}{ }_{1}=\frac{X_{i j} / X_{i t}}{X_{w j} / X_{w t}}
$$

Formülde, 'i' rekabeti yapılan mal, 'j' rekabet yapan ülke, 'w' toplam dünya ihracatı, ' $x$ ' ise ihracatı temsil etmektedir. Endeks ölçümü neticesinde sonuç 1'den büyükse, ülkenin karşılaştırmalı üstünlüğe sahip olduğu; endeks değeri 1'den küçükse, karşılaştırmalı dezavantajı olduğu anlaşılmaktadır (Yurtançıkmaz ve Emsen, 2020).

Çin'in ABD veya bu ülkenin de dahil olduğu ülkeler açısından rekabet gücündeki gelişmelere ilişkin olarak literatürde bir kısım çalışmalar bulunmaktadır. Bu çalışmaları özet olarak şu şekilde vermek mümkündür:

Li (2018) Çin'in ileri teknoloji imalat sanayisinin ABD, Almanya, Japonya, Fransa, Güney Kore piyasasındaki ulusal rekabet gücünü belirlemek amacıyla araştırma yapmıştır. Bu çalışma 1995-2011 dönemini kapsamaktadır. Balassa endeksinden hareketle elde edilen sonuç; Çin'in yüksek ileri teknoloji imalat sanayisindeki rekabet gücünün yükseldiğini, ancak bu yükselişin endüstriyel bazda farklılık gösterdiğini, yeni kimyasal ürünler ve ulaşım ekipmanları sektöründe hala karşılaştırmalı üstünlüğe sahip olmadığını, bununla birlikte mekanik ekipman sektöründe karşılaştırmalı üstünlüğe sahip olduğunu ve elektronik ekipman endüstrisinde ise karşılaştırmalı üstünlüğünün daha da arttığını ortaya koymuştur.

Dai (2015) Çin'in 1995-2011 yılları arası imalat sanayinin ulusal rekabet gücünü karşılaştırmalı üstünlükler endeksiyle araştırmıştır. Analiz sonucu; emek yoğunluklu endüstrilerde daima yüksek ulusal rekabet gücüne sahip olduğunu, ancak bu avantajın son zamanda azalmaya başladığı ileri sürülmüştür. Sermaye yoğun endüstrilerde ise Çin, göreceli karşılaştırmalı üstünlüğe sahip olmasa bile, son zamandaki rekabet gücündeki yükseliş ile emek yoğunluklu sektörün 
karşılaştırmalı üstünlüğünün zayıflaması, ardından sermaye yoğunluklu sektörün karşılaştırmalı üstünlügün arttığı tahmin edilebilmektedir. Bilgi ve teknoloji yoğunluklu sektörlerde ise gelişmiş ülkelere göre büyük gerilik vardır ve kısa bir sürede yakalama imkanı da yoktur.

Yu ve Ji (2017) ise, ABD'nin rekabet gücünü artırmak ve istihdam yaratmak için uyguladığı düşük döviz kurunun, yabancı yatırımların geri dönüşünü tetikleyerek Çin'in imalat sanayinin dönüşümünü ve iyileştirilmesini olumsuz yönde etkilediğini ortaya koymuştur. AKÜ verileriyle Çin'in imalat sanayi ticaret rekabet gücü üzerine yaptıkları analizlerde Çin'in imalat sanayisinin rekabet gücünün genel olarak yüksek olmamasına rağmen, teknolojik ürünlerde gerek $\mathrm{ABD}$, gerek ulusal piyasada rekabet gücüne sahip olduğu tespit edilmiştir.

Mao (2006) Çin'in imalat sanayisinin ABD, Japon, Almanya, İngiltere, Fransa, Hollanda, İtalya, Avustralya, Güney Kore, Tayvan, Hong Kong, Tayland, Malezya, Filipinler, Endonezya'ya göre karşılaştırmalı üstünlük endeksini 19942004 yılları arasındaki verilerini kullanarak hesaplamıştır. AKÜ endeksi analizinden, Çin'in düşük teknoloji sanayi üretiminde uzmanlaştığını ve bunda yüksek rekabet gücüne sahip olmasının yanı sıra, birçok ileri teknoloji sanayi üretiminde, özellikle bilgi ve iletişim teknolojileri üretiminde karşılaştırmalı üstünlügünü çarpıcı bir biçimde arttırdığı belirlemesinde bulunmuştur. Gelişmiş ülkelere göre bu sektörün AKÜ endeksi düşük teknoloji sanayinde zaten yüksek olduğu tespit edilmiştir.

\section{3. Çin ile ABD Rekabet Gücü}

Çalışmada UNCTAD veri setinden yararlanılmış olup, Çin ile ABD arasındaki rekabet gücü karşılaştırılırken, bir tür dünya ekonomisinin fabrikası fonksiyonunu üstlenmeye başlayan Çin'in dünya ekonomisinin en gelişmiş ülkesi olan ABD ile rekabet gücü de hesaplanması yoluna gidilmiştir.

Şekil 2'de Çin'in seçilmiş 10 temel mal grubu itibarıyla dünya pazarındaki ihracatı ve ithalatı verilmiştir. 
Çin ile ABD Arasında Ticari Gerginlik: Rekabet Gücü Açısından Bir Bakış

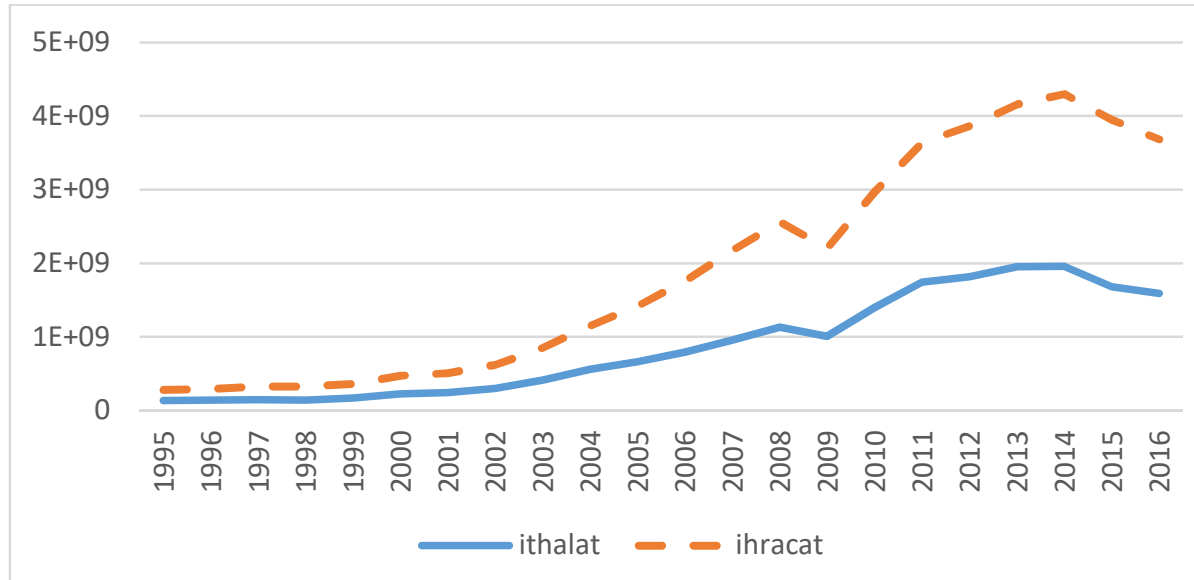

Şekil:2 Çin'in Seçilen Temel 10 Mal Grubunda Dünya Pazarındaki Toplam Ihracat ve Ithalatı

Şekilden de görüleceği gibi, 1995-2008 yılları itibariyle Çin'in dünyaya yaptığı toplam ihracat ve toplam ithalat miktarında yükselişin olduğu görülmektedir. ABD'nin subprime-mortgage krizinin tetiklediği uluslararası mali krizden etkilenen Çin'in dış ticareti, yani ithalat ve ihracat artış hızı 2008 sonu ve 2009 yılında düşük seviyelerde seyretmiştir. Buna karşılık GSYIHH'nın hızlı büyümesini sürdürmek için, Çin hükümeti iç talebi canlandırmak amacıyla 4 trilyon yatırım yapmış ve bunun sonucu ülke ekonomisi yükselmeye başlamış, ancak 2015 sonrası ise ülke ekonomisinde daralma görülmüştür.

Çin'in 2008'deki ekonomik gerilemesinin nedenleri başlıca beş açıdan ortaya çıktığı söylenebilir:

1. Aşırı kapasite, sabit yatırımın reel büyüme oranında önemli bir düşüşe yol açmaktadır. 2003'ün ikinci yarısından itibaren Çin'in yatırım artışı çok hızlı olmuştur. 2005'ten bu yana bazı büyük endüstrilerde değişken derecelerde aşırı kapasite görülmüştür. Ulusal Kalkınma ve Reform Komisyonu tarafindan yayınlanan bilgiye göre, 2005 yılı sonunda Çin, çelik, elektrolitik alüminyum, otomobiller, ferroalyajlar, kok kömürü, kalsiyum karbür ve bakır eritme, çimento, elektrik, kömür ve tekstil gibi 11 sektörde potansiyel fazla kapasite taşımaktadır (Tian ve Wang, 2009).

2. Renminbi'nin keskin değer kazanmaya devam etmesi ve ihracatta vergi iadesi oranlarındaki artışın azalması ihracat şirketlerinin zorluklarla karşılaşmasına neden olmuştur. RMB döviz kuru oluşum mekanizması reformunun ardından 21 Temmuz 2005 'te yuan, ABD doları karşısında değer kazanmaya devam etmiştir (Tian ve Wang, 2009).

3. 2004'ten 2007'ye kadar, GSYİH büyüme hızı ard1 ardına beş yıl boyunca \%10'u aşmış ve bu da potansiyel GSYİH büyüme oranından daha yüksek olmasına neden olmuştur. Aynı zamanda Haziran 2007'den bu yana da tüketici fiyat endeksi (CPI)'deki artış \%4'ün üzerine çıkarak, enflasyon 
tehlikesini artırmıştır. Ekonominin aşırı 1sınmasını önlemek için, Çin Halk Bankası 2003 yılının ilk yarısından bu yana istikrarlı bir şekilde daraltıcı para politikası uygulamıştır. Daraltıcı para politikası, işletmelerin sadece kredi alma zorluğunu (özellikle KOBİ'lerin kredi alma zorluğunu) arttırmakla kalmamış, aynı zamanda işletmeler üzerindeki faiz yükünün de artırmasına neden olmuştur (Tian ve Wang, 2009).

4. Toplumun güvenindeki düşüş, daraltıcı politika esnasında biriken enerjinin açığa çıkmasına yol açmışır. Ekonominin aşırı 1sınmasını önlemek için hükümet, son yıllarda makroekonomik politikaların odak noktası olarak sabit kıymetlerdeki yatırımın aşırı büyümesini kontrol etmektedir. Ancak, daraltıcı makroekonomik politikaların etkisi, kamuoyunun beklentileri ve dünyanın çeşitli ülkelerinde emtia fiyatlarındaki genel artış nedeniyle tam olarak ortaya çıkmamış, yüksek ekonomik büyüme oranları ve aşırı fiyat artışlarıyla gölgelenmiştir. Ardışık daraltıcı politikalar benimsenmiş ve daraltıcı politika uygulamaları sürekli artmıştır. Sonuç olarak, daraltıcı politikalarının sıkılaştırıcı enerjisi birikmeye devam etmektedir. Rakamlar, 2008 yılı Ekim ayında tüketici güven endeksinin Ocak ayına göre 3,2 puan azalarak 92,4 olduğunu, 2008 yılının Ekim ayında ise Çin'in imalat sanayi yöneticileri endeksinin Ocak ayına göre 8,4 puan azalışla 44,6 seviyesinde olduğunu göstermektedir. ABD finansal krizinin patlak vermesi sonucu krizin Çin ekonomisi ve finansmanı üzerindeki etkisinden de endişenin artmasını harekete geçirmiştir (Tian ve Wang, 2009).

5. Ekonomik anlamda gösterdiği performansın altında kalışının nedenini birçok kişi, ABD finansal krizine bağlamıştır. Ancak, Çin'de mevcut ekonomik krizin ABD finansal krizi ile ilgisi çok da fazla bağlantılı görünmemektedir. Şöyle ki, Çin İstatistik Ulusal Bürosu tarafından yayınlanan "Çin Aylık Ekonomik Göstergeler" rakamları 2007 yılının ikinci çeyreğinde Çin'in ekonomik büyüme oranının son yılların en yüksek değerin \%12.7 ulaştı̆̆ını ve sonra azalmaya devam ettiğini göstermektedir. İlk düşüşün, makro kontrolün beklenen hedefleri ile uyumlu olması, ekonominin iyi bir performansı için beklenen bir durumdur. 2008'e girdikten sonra, ekonomik büyüme oranı daha da düşmüş, ilk çeyrekte \%10,6'ya, ikinci çeyrekte \%10,2'ye ve üçüncü çeyrekte \%8,9'a gerilemiştir. Buna karşılık, 2008 yılının ikinci çeyreğinde önce ABD ekonomisi artmış ve ilk çeyrek büyüme oranı $\% 2.5$, ikinci çeyrekte $\% 2.1$, bir önceki yılın aynı dönemine göre biraz daha düşük, ancak bir önceki çeyreğe göre $\% 2,8$ artış olmuştur. Bu veriler şu sonuçlara işaret etmektedir: Birincisi, Çin ekonomisindeki düşüş, $\mathrm{ABD}$ ekonomisindeki düşüşe göre daha erken olmuş; ikincisi 2007 yllının üçüncü çeyreğinde ABD alt kredi krizi oluşmuş ve 2008 yılının ilk yarısında ABD ekonomisi üzerinde çok etkisi olmamıştır. Bu veriler değerlendirildiğinde, Çin ekonomisinin 2008'in ilk yarısındaki düşüşünün ABD finansal krizi ve dünya ekonomik krizi ile doğrudan ve kaçınılmaz bir bağlantısı olmadığını göstermektedir (Tian ve Wang, 2009).

Aşağıda $A B D$ ve Çin arasında temel mal grupları itibarıla rekabet güçlerindeki gelişmeler verilmiştir. Yukarıda da belirtildiği gibi Balassa 
endeksine göre rekabet gücü, endeks değerinin 1'in üzerinde olması halinde rekabet gücü yüksek; 0.5 ila 1 arasında ise ilgili malda karşılaştırmalı sınırlı; 0.5 'den küçük ise karşılaştırmalı üstünlük düşüktür. Dolayısıyla 10 temel mal grubu için hesaplanan endeks değerine göre bu gelişmeler de üç ana grupta ele alınmıştır. Birinci grupta Çin'in ABD karşısında rekabet gücünün olduğu mal grupları yer almaktadır. İkinci grupta ise ABD karşısında rekabet gücü olmayan, ancak zamana bağlı olarak rekabet gücünde gelişme kat ettiği mal grupları bulunmaktadır. Üçüncü grupta ise kesinlikle rekabet gücü olmayan ve gelişim de göstermeyen mal grupları yer almaktadır. Aşağıdaki şekilde Çin'in ABD karşısında rekabet gücünün olduğu mal grupları yer almaktadır.

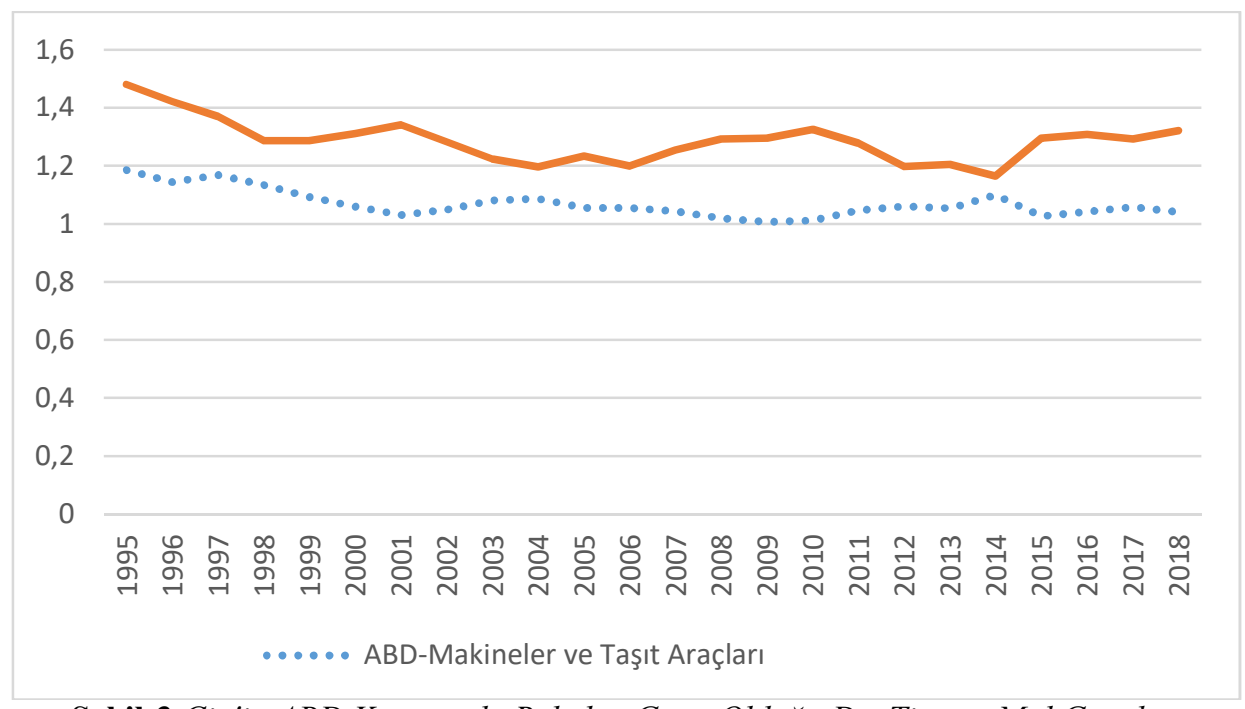

Şekil:3 Çin'in ABD Karşısında Rekabet Gücü Olduğu Dış Ticaret Mal Grupları

Çin'in genel olarak ABD karşısında üstün olduğu mal grubu iki ana grupta yer alanlardır. Bu noktada Çin'in ABD'ye karşı en üstün olduğu mal grubu "makineler ve taşıt araçları" ile "çeşitli mamul eşya" şeklindedir. Çin'in ABD karşısında üstün olmamakla birlikte zamana bağlı olarak üstünlük kurması kuvvetle muhtemel sektörler ise aşağıdaki şekilde gösterilmiştir. 


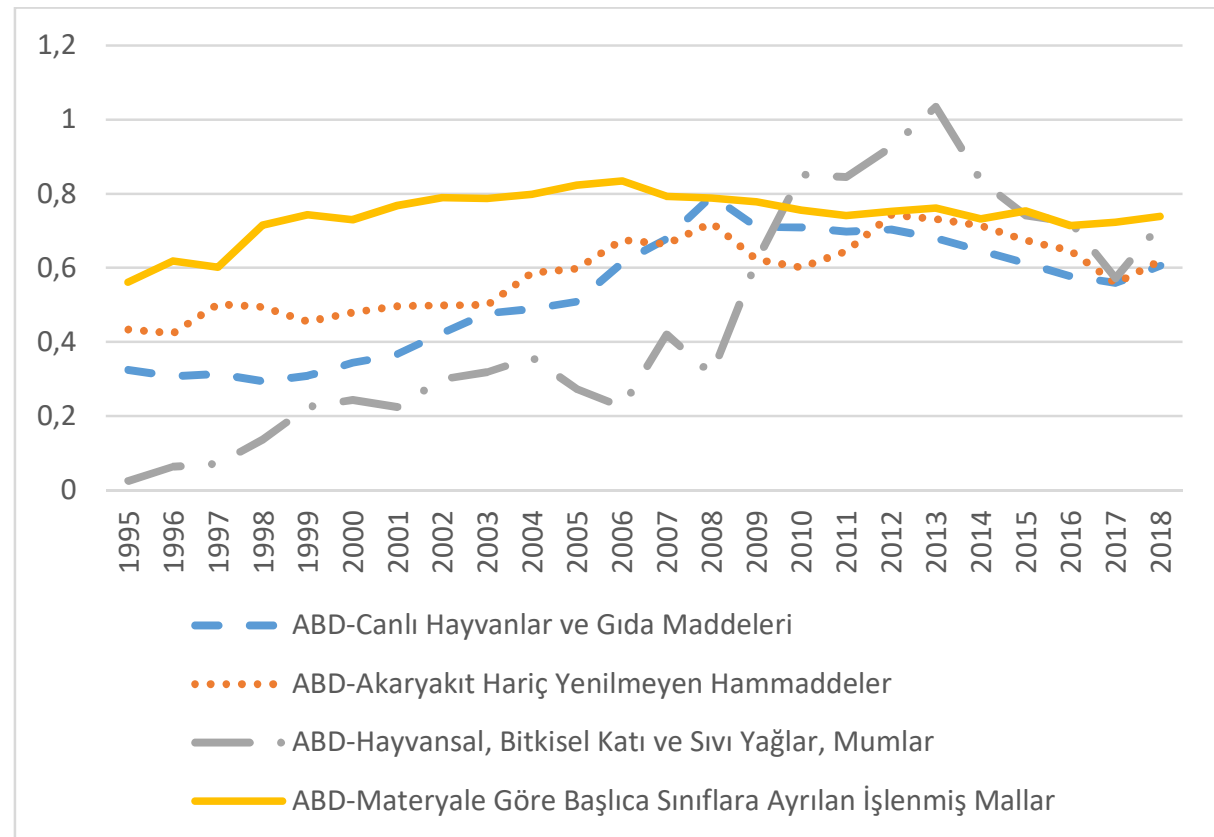

Şekil:4 Çin'in ABD Karşısında Rekabet Gücü Olmayan Ancak Iyileşme Gösteren Dış Ticaret Mal Gruplarl,

Burada dört mal grubunda Çin'in özellikle 2008 küresel krizine kadarki süreçte rekabet gücü elde etme yolunda bir trend izlediği gözükmektedir. Ancak, küresel krizin bu süreci bir tür sekteye uğrattığı söylenebilir. Rekabette avantaj elde edeceği düşünülen bu dört mal grubu içerisinde sirasıyla "hayvansal ve bitkisel katı ve sıvı yağlar, mumlar", "canlı hayvanlar ve gida maddeleri" ve "akaryakıt hariç yenilmeyen hammaddeler" grubunda dalgalı bir rekabet gücünün varlığına rağmen, rekabet gücünü elde etme yolunda istikrarlı bir trendin varlığından söz edilebilir. Bu dört mal grubu içerisinde diğer üç mal grubuna göre başlangıçta daha yüksek bir rekabete erişme yolundaki yapıya rağmen, bu mal grubunun hemen hemen aynı düzeylerde kalarak rekabetçi yapı elde etme başarısı gösteremeyeceği dikkat çekmektedir.

Üçüncü grupta ise Çin'in ABD karşısında kesinlikle dezavantajlı olduğu mal grupları bulunmaktadır ve bu mal gruplarına ilişkin endeks değerinin zamana bağlı olarak gelişimi aşağıdaki şekilde verilmiştir. 
Çin ile ABD Arasında Ticari Gerginlik: Rekabet Gücü Açısından Bir Bakış

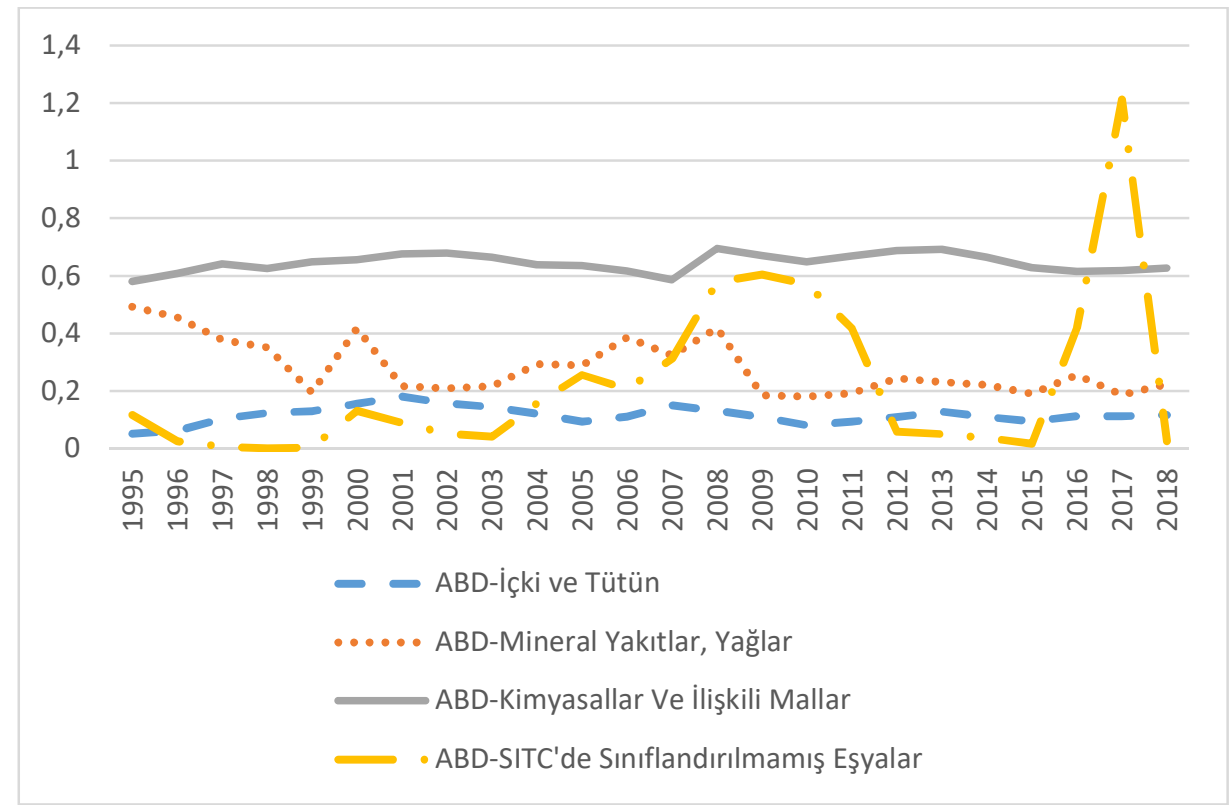

Şekil:5 Çin'in ABD Karşısında Rekabet Gücü Olmayan ve Gelişim Göstermeyen Dış Ticaret Mal Gruplarl,

$\mathrm{Bu}$ grupta en dezavantajlı olunan mallar da sırasıyla "sınıflandırılmamış eşyalar", "içki ve tütün", "mineral yakıtlar, yağlar" ve "kimyasallar ve ilişkili mallar" şeklinde sıralanmaktadır. Rekabet güçleri açısından değerlendirme yapılacak olduğunda, Li (2018), Dai (2015), Yu ve Ji (2017) ile Mao (2006) tarafindan yapılan çalışmalar ile benzeşiklik gösterdiği; Çin'in özellikle zamana bağl1 olarak düşük teknoloji sanayi üretiminden ileri teknoloji sanayi üretimine doğru rekabet gücünün evrildiği görülmektedir.

\section{Sonuç}

Çalışmanın motivasyonunu oluşturan Çin ekonomisi halihazırda "dünyanın fabrikası" olarak nitelendirilmektedir. Özellikle büyük nüfus potansiyeline bağlı olarak emek-yoğun sektörlerde başlayan büyük hamleler zamana bağlı olarak dönüşüm göstermeye devam etmekte ve günümüzde de yüksek teknoloji mal ihracatına evrilen bir yapı sergilemektedir. Bu gelişim eşliğinde ABD'nin özellikle geçmişte başta Japonya olmak üzere zaman zaman başvurduğu "gönüllü ihracat kısıtlamaları" argümanı; Çin özelinde de işletilmeye başlanmıştır. Bunun en somut örneği de 2018 'de başlatılan "ticaret savaşı" kavramında kendine yer edindiği söylenebilir ki, bu yönüyle Çin, ABD’yi rekabet gücü açısından sıkıştırarak adeta ekonomik hegemonyasını tehdit eder bir unsur halini aldığı düşünülmektedir. Dolayısıyla alt sektörler bazında Çin'in ABD karşısında rekabet gücü incelemeye değer konumdadır. 
Çin ve ABD'nin temel 10 mal gurubunda birbirileri karşısındaki rekabet gücünün belirlenmesi ve iki ülkenin geçmiş sanayi tarihi incelenen bu çalışmada kullanılan veriler 1995 ile 2016 aralığını kapsamıştır. Çalışmada kullanılan veriler Birleşmiş Milletler Ticaret ve Kalkınma Konferansı'nın (UNCTAD) internet sitelerinde yer alan veri dağıtım servislerinden elde edilmiştir. Bu noktada küreselleşen ekonomi dünyasında dış ticarette avantaj sağlayabilmek ve katma değer elde etmek için belli ürün veya sektörde diğer ülkelere göre rekabet gücüne sahip olmak önemlidir.

ABD ile Çin arasındaki rekabet gücü hesaplamaları sonucu elde edilen bulguları şu şekilde özetleme mümkündür:

Çin'in ABD karşısında hesaplanan temel 10 mal guruplarının AKÜ endeksine göre, Makineler ve Taşıt Araçları, Çeşitli Mamul Eşya, iki mal gurubundaki Balassa endeksi 1'den büyük görülmekte ve bu da rekabet gücüne sahip olduğunu göstermektedir.

Diğer 8 mal grubunda ise rakamlar 1'den küçüktür ve dolayısılyla rekabet gücüne sahip olmadığına işaret etmektedir. Ancak, Çin'in rekabet gücünde zayıflık bulunan sektörlerden dördünde zamana bağlı olarak ABD karşısında rekabet gücünde gelişme gösterdiği; başlangıçta gözlenen açık dezavantajlı yapının zamanla nötrleşme eğilimi içerisinde olduğu söylenebilir.

Çin'in ABD sanayisinin genel durumları açısından bir değerlendirme yapılacak olduğunda, Çin'in ABD karşısında halen daha emek yoğunluklu bir yapıda olduğu gözlenirken, özellikle son dönemlerde rekabet gücünün sermaye ve teknoloji yoğunluklu mallarda Çin lehine bir trendin olduğu dikkat çekmektedir. Çin'in aşırı derecede ihracata ve emek yoğunluklu üretime dayanan iktisadi büyümesinin ülke ekonomisine önemli katk1larda bulunduğu dikkat çekmekte ve kentleşme oranı da dikkate alındığında, Çin'in kırsalda önemli denebilecek bir emek deposunun varlığı, emek yoğun büyümeyi sürdürme potansiyeline işaret etmektedir. Ancak, Çin'in özellikle gelişmiş ülkeler karşısında rekabet gücüne sahip olabilmesi için sermaye yoğunluklu ve yüksek teknoloji içeren sektörlerin gelişimine devam etmesi gerektiği açıktır ki, bu noktada Ar-Ge'ye önem verilmesi ve verimlilik artışında sürekliliği sağlaması gerekmektedir. Çin deneyiminden hareketle 1980 'de diş ticaret politikasında radikal bir dönüşüme giden Türkiye ekonomisinin emek-yoğun sanayi alanında başlayan gelişiminin teknolojik gelişime dönüşümünde Çin'in yaşadığı deneyimden dersler çıkarması faydalı olacaktır.

\section{Kaynaklar}

Acemoğlu, D. ve James A. R, (2014), Ulusların Düşüşü: Güç, Zenginlik ve Yoksulluğun Kökenleri, (Çev. F. R. Velioğlu), Doğan Kitap, İstanbul.

Azgün, S., ve Yurttançıkmaz, Z. Ç., (2017) “Türkiye ve OECD Ülkeleri Arasında Düşük, Orta ve Yüksek Teknolojili İmalat Sanayi Sektörlerinde Endüstri 
Çin ile ABD Arasında Ticari Gerginlik: Rekabet Gücü Açısından Bir Bakış

İçi Ticaretteki Değişimler” Atatürk Üniversitesi İIBF Dergisi, 31(2), 397411.

Coase, R. H. ve Ning W., (2015), Çin Nasıl Kapitalist Oldu?, (Çev. İ. Yılmaz), Tarcan Matbaasi, Ankara.

Deng, X. P., (1994), Deng, Xiao Ping, Vol. 2 [M], Beijing: People's Publishing House. 邓小平文选(第 2 卷)[M].北京: 人民出版社.

Durand, M. and Claude G., (1997),'Indicators of International Competitiveness", Conceptual Aspects and Evaluation, (5): 147-197.

Fukuyama, F., (1999), Tarihin Sonu ve Son İnsan, (Çev. Z. Dicleli), Gün Yayınları, İstanbul.

Gu, M., (2009), “The Brewing and Start of China's National Policy of Opening to the Outside World [J]”, Party Literature, (1): 24-31，谷牧.我国对外开 放国策的酛酿和起步 [J].党的文献, (1), 24-31.

Han, B., J. and Yang, L., (2019), "70 Years of Industrialization, Achievements and Basic Experience in New China”, Reform, (8): 57-65. 韩保江和杨 丽，新中国70年工业化历程、成就与基本经验，改革，第 5 期.

Hao, L., (2004) The Competitiveness of Canada's Poultry Processing Industry. A thesis for the degree of Master of Science. McGill University,Canada, 9, $11,22,42,65,68 \sim 72,74$.

Huang, Q., H., (2018). "China's Industrial Development and Industrialization Process in the 40 Years of Reform and Opening [J]", China Industrial Economy, (9): 5-23. 黄群慧. 改革开放 40 年中国的产业发展与工业 化进程 [J] . 中国工业经济.

Huntington, S., P., (2000), Medeniyetler Çatışması, (Derleyen: M. Yılmaz), Vadi Yayınları, Ankara.

Kaynak, M., (2011), Kalkınma İktisadı, Gazi Kitapevi. Gözden Geçirilmiş ve Genişletilmiş 4. Baskı, Ankara.

Kazgan, G., (2005), Küreselleşme ve Ulus-Devlet: Yeni Ekonomik Düzen, İstanbul Bilgi Üniversitesi Yayınları, İstanbul, 2005.

Kennedy, P., (1990), Büyük Güçlerin Yükseliş ve Çöküşleri (1500'e 2000'e Ekonomik Değişme ve Askeri Çatışmalar), (Çev. B. Karanakçı), Türkiye İş Bankası Kültür Yayınları, Ankara.

Li, L., (2018), Research on 40 Years of Achievements and Basic Experiences of China's Reform and Opening Up, (Graduate Thesis). Qufu: Normal University. 李丽，中国改革开放40年成就及基本经验研究，曲阜师 范大学研究生学位论文.

Maalouf, A., (2012), Arapların Gözünden Haçlı Seferleri, (Çev. A. Berktay), Yapı Kredi Yayınları 2375, İstanbul. 
Peng, Y., (2010), Research on the Competitiveness Structure of China's Textile Industry, (Graduate Degree Thesis), Shanghai: Academy of Social Sciences. 彭羽，中国纺织工业竞争力结构提升研究，上海社会科学 院，研究生毕业学位 论文

Reziwanguli, Y., (2019), Çin'in ABD ve Türkiye Ekonomisi Karşısındaki Rekabet Gücü Üzerine Incelemeler, Atatürk Üniversitesi Sosyal Bilimler Enstitüsü, (Yayınlanmamış Yüksek Lisans Tezi), Erzurum.

Tian, Q., S., and Yuan L., W., (2009), "China's Economic Downturn: Causes and Responses[J]”, Economics and Management Studies, (3): 16-21.田秋生, 王元龙. 中国经济下滑:原因与应对 [J]. 经济与管理研究

Ülken, H., Z.,, (2016), Yeni Zamanlar Felsefesi, (Yayına Hazırlayan: H. Aydın), Türkiye İş Bankası Kültür Yayınları, İstanbul, 2016.

Yurttançıkmaz, Z. Ç., Kabadayı B. ve Emsen, Ö., S., (2014), "Ekonomik Büyüme ve Rekabet Gücü Üzerine Türkiye Analizi”, İstanbul Üniversitesi İktisat Fakültesi Ekonometri ve İstatistik Dergisi, 21: 21-46. 